\title{
KAJIAN PRO KONTRA PENERAPAN SISTEM ZONASI PENDIDIKAN DI INDONESIA
}

\section{STUDY OF PROS AND CONS OF EDUCATIONAL ZONING SYSTEM IN INDONESIA}

\author{
Nandy Agustin Syakarofath \\ Fakultas Psikologi Universitas Muhammadiyah Malang, Indonesia \\ E-mail: nandysyakarofath@umm.ac.id
}

\author{
Ahmad Sulaiman \\ Fakultas Psikologi Universitas Muhammadiyah Malang, Indonesia \\ E-mail: sulaiman_ahmad@umm.ac.id
}

\author{
Muhamad Faqih Irsyad \\ College of Education, Psychology and Social Work, Flinders University, Australia \\ E-mail: irsy0001@flinders.edu.au
}

Naskah diterima tanggal: 04-09-2020, disetujui tanggal: 02-12-2020

\begin{abstract}
Indonesia strives for enhancing educational equality through a zoning system that regulates new student admission based on the distance between school and student's residence. However, the implementation of the system in 2019 caused pros and cons amongst Indonesian society. This study comprehensively reviews the historical backgrounds, objectives, advantages and challenges, as well as their solutions of implementing the zoning system. This study used the narrative review method by collecting, synthesizing, analyzing and analyzing the results from various sources and relevant data.The results revealed that the successful of zoning system implementation in other countries were supported by their alignment with other national education policies, such as infrastructure acceleration and teacher development. The implementation of the zoning system is not only for improving education quality, but also encouraging the active participation of schools and parents in education planning. The main challenge in implementing zoning system is the lack of readiness of affected stakeholders. In addition, the implementation of the zoning system requires improvement, particularly in its implementation at the local level. The solution to respond to these challenges is by earlier socialization of zoning system and sharpening operational policies in the regions. To conclude, the application of the zoning system has caused positive and negative responses for education stakeholders. To achieve the acceptable and implementable of zoning system in the long term, the government should translate policy goals and objectives according to local conditions, communicate zoning policies accurately, and involve the community.
\end{abstract}

Keywords: schools, zoning system, pros and cons, primary and secondary education

Abstrak: Indonesia berupaya meningkatkan pemerataan pendidikan melalui sistem zonasi yang mengatur penerimaan peserta didik didasarkan pada jarak sekolah dengan tempat tinggal calon peserta didik. Penerapan sistem tersebut pada Penerimaan Peserta Didik Baru (PPDB) tahun 2019 menuai pro-kontra yang tajam di tengah masyarakat. Untuk memahami pro-kontra tersebut, studi ini bertujuan mengkaji secara komprehensif latar historis penerapan sistem zonasi di beberapa negara, tujuan, keuntungan dan tantangan, serta solusi mengatasi persoalan penerapan sistem zonasi. Studi ini menggunakan metode 
Nandy Agustin Syakarofath, Ahmad Sulaiman, \& Muhamad Faqih Irsyad, Kajian Pro Kontra Penerapan Sistem Zonasi Pendidikan di Indonesia

narrative review dengan menghimpun, membuat sintesis, dan menganalisis hasil dari berbagai sumber dan data yang relevan. Hasil kajian mengungkapkan bahwa keberhasilan pelaksanaan sistem zonasi di negara-negara lain ditopang oleh keselarasan dengan kebijakan nasional pendidikan pendamping, seperti akselerasi pembangunan infrastruktur dan SDM guru. Penerapan sistem zonasi tidak hanya bertujuan untuk pemerataan kualitas pendidikan, namun juga mendorong partisipasi aktif sekolah dan wali murid dalam perencanaan Pendidikan. Tantangan utama dalam penerapan kebijakan zonasi adalah kurangnya kesiapan pemangku kepentingan yang terimbas. Selain itu, penerapan sistem zonasi di Indonesia memerlukan pembenahan utamanya dalam pelaksanaan di tingkat lokal. Solusi untuk merespon tantangan tersebut adalah dengan mengkampanyekan kebijakan sistem zonasi lebih dini dan melakukan penajaman kebijakan operasional di daerah. Kesimpulan, penerapan sistem zonasi menimbulkan tanggapan positif dan negatif bagi para pemangku kepentingan pendidikan, terutama siswa, orangtua, dan guru. Agar sistem zonasi dapat diterima masyarakat dan implementatif dalam jangka panjang, pemerintah hendaknya menerjemahkan tujuan dan sasaran kebijakan sesuai dengan kondisi lokal, mengomunikasikan kebijakan zonasi secara akurat, dan melibatkan masyarakat melakukan pemantauan dan evaluasi.

Kata kunci: sekolah, sistem zonasi, pro kontra, pendidikan dasar dan menengah

\section{PENDAHULUAN}

Dalam skala global, dapat kita amati bahwa telah dan masih terjadi di seluruh penjuru dunia suatu gerakan reformasi pendidikan yang sistematis mengarah kepada pemuasan ideologi pasar internasional, neoliberalisme (Lakes \& Carter, 2011). Cheng (2020) menilai bahwa tuntutan reformasi pendidikan ini selain karena kepentingan elite ekonomi raksasa, juga karena keinginan masyarakat lokal dalam memperbaiki kehidupan generasi berikutnya dengan meningkatkan akses sekaligus kualitas pendidikan secara umum. Dengan demikian, reformasi pendidikan memiliki dua kutub penggerak, yaitu dari atas (top-driven) dan dari bawah (bottomdriven). Kedua kutub itu harus berjalan beriringan bila menginginkan reformasi yang berkelanjutan.

Cheng (2020) menyampaikan kekhawatirannya terkait dua sisi mata pisau dari reformasi pendidikan. Reformasi akan mendorong perubahan yang seringkali radikal yang menyebabkan tatanan lama terguncang sehingga menciptakan imbas penolakan kepada kebijakan yang reformatif. Dengan demikian, kondisi pendidikan bisa stagnan di suatu titik atau malah berjalan mundur. Kondisi yang demikian, nampaknya sedang terjadi sejak tahun 2018, kala pemerintah mewacanakan sistem zonasi pendidikan.

Secara normatif, Indonesia menerapkan program wajib belajar 12 tahun, kombinasi dari sekolah dasar (6 tahun), sekolah menengah pertama ( 3 tahun), dan sekolah menengah atas (3 tahun). Tujuan utama dari program wajib belajar 12 tahun ini adalah untuk membangun angkatan kerja Indonesia yang produktif yang dapat menjawab kebutuhan pasar akan sumber daya terampil demi menyongsong kompetisi ekonomi dunia global (Hasanah \& Jabar, 2017; Ismanto, Tagela, \& Wasitohadi, 2017; Ratnawati, Suwitri, \& Rengga, 2013).

Demi terwujudnya pemerataan akses dan terjangkaunya layanan pendidikan oleh masyarakat, pemerintah telah melakukan berbagai upaya, salah satunya dengan menerapkan sistem zonasi. Sistem zonasi adalah sistem yang mewajibkan anak didik untuk mengenyam pendidikan di sekolah yang radiusnya terdekat dari tempat tinggalnya (Wahyuni, 2018). Sejak penerimaan peserta didik baru tahun ajaran 2017 pemerintah telah telah mencanang program zonasi. Meski demikian, penerapan kebijakan ini masih dilaksanakan secara bertahap dan dalam 
proses adaptasi oleh pemerintah di tingkat lokal (Wahyuni, 2018). Pada tahun 2019, pemerintah menerapkan sistem zonasi secara serentak di jenjang SMP dan SMA.

Dua tujuan utama penerapan sistem zonasi di lingkungan pendidikan adalah pemerataan kualitas pendidikan dan menghapus label sekolah favorit dan tidak favorit (Safarah \& Wibowo, 2018; Wahyuni, 2018). Sebelumnya, dualisme label sekolah favorit dan nonfavorit atau sistem kelompok di tengah masyarakat membuat sekolah-sekolah seolah terkotak-kotak. Munculnya stigma yang beredar luas di masyarakat yang menganggap rendahnya kualitas siswa yang bersekolah di sekolah tidak favorit. Hal ini merugikan bagi sekolah-sekolah tidak favorit sebab mereka tidak menjadi prioritas bagi siswa-siswa untuk melanjutkan sekolah (Safarah \& Wibowo, 2018).

Merespon kondisi itu, dibutuhkan kebijakan yang mengatur kondisi ketimpangan tersebut, salah satunya melalui sistem zonasi yang dianggap memiliki banyak manfaat khususnya pada pemerataan pendidikan (Safarah \& Wibowo, 2018; Wahyuni, 2018). Manfaat lain dari sistem zonasi adalah dapat mendorong siswa untuk berjalan kaki dan bersepeda ke sekolah (Wilson, Marshall, Wilson, \& Krizek, 2010). Ketergantungan terhadap transportasi bermotor menjadi berkurang (Mandic, et al., 2017). Hal ini membantu meningkatkan kesehatan fisik siswa dan mengurangi tingkat emisi di udara akibat bahan bakar kendaraan bermotor. Meski demikian, mulianya tujuan dari sistem zonasi, kebijakan ini sebagaimana layaknya suatu kebijakan baru, menuai pro dan kontra di tengah masyarakat (Aritonang, 2011).

Dalam penelitian sebelumnya, Wahyuni (2018) menyebutkan perdebatan yang terjadi di masyarakat terkait sistem zonasi terbagi menjadi tiga tema besar. Pertama, prioritas jarak tempat tinggal calon peserta didik dengan sekolah sebagai penentu utama PPDB yang dirasa tidak pas karena ketersediaan sekolah di daerah tidak seimbang sehingga beberapa sekolah kekurangan peserta didik. Kedua, perbedaan penafsiran terkait implementasi aturan zonasi sehingga penerapannya berbeda di setiap sekolah dan daerah. Ketiga, penggunaan Surat Keterangan Tidak Mampu (SKTM) yang dalam praktiknya menjadi peluang kecurangan.

Kontra penerapan sistem zonasi sempat menjadi tajuk utama dari berbagai media lokalnasional dalam selang waktu 2017-2019. Laporan banyaknya protes yang dilakukan masyarakat terkait sistem zonasi. Misalnya, di Yogyakarta orangtua siswa melakukan pengaduan ke anggota DPRD DIY, ke Ombudsman RI, dan Lembaga Ombudsman Daerah (LOD) terkait sistem zonasi yang dipandang mendiskriminasi hak siswa untuk sekolah (Kusuma, 2019). Kejadian serupa terjadi di kota Malang. DPRD Kota itu melayangkan protes kepada Kemendikbud atas aduan masyarakat yang merasa dirugikan karena banyak peserta didik yang gagal masuk ke sekolah terdekat padahal mereka berada dalam zonasi (Aminudin, 2019). Sistem zonasi sebagai suatu sistem baru memiliki berbagai permasalahan penerapan di lapangan karena minimnya kesiapan perangkat sekolah, jumlah dan kualitas sekolah tujuan calon siswa baru, dan kerancuan dalam penafsiran kebijakan oleh pemerintah lokal dan pimpinan sekolahsekolah (Wahyuni, 2018).

Meskipun demikian, pemerintah masih bersikukuh menerapkan kebijakan zonasi. Pergantian dari Mendikbud Muhadjir Effendi kepada Nadiem Makarim juga masih melanjutkan kebijakan penerapan sistem zonasi. Sebagian masyarakat yang menjadi komponen kebijakan zonasi menilai bahwa keuntungan jangka panjang yang akan diraih dari penerapan system zonasi akan jauh melampaui kelemahan yang saat ini dirasakan (Safarah \& Wibowo, 2018).

Mempertimbangkan berbagai permasalahan yang dihadapi di lapangan dan penolakan yang beredar di kalangan masyarakat perlu untuk 
Nandy Agustin Syakarofath, Ahmad Sulaiman, \& Muhamad Faqih Irsyad, Kajian Pro Kontra Penerapan Sistem Zonasi Pendidikan di Indonesia

diteliti kebijakan zonasi dari berbagai komponen, untuk kemudian memproyeksikan langkah berikutnya dalam mengoptimalisasi kebijakan yang sudah ada. Komponen tersebut di antaranya adalah komponen historis dari kebijakan sistem zonasi, baik dari sisi global dan domestik; persepsi masyarakat yang menolak; dan argumentasi yang digunakan pendukung penerapan sistem zonasi. Ketiga elemen tersebut akan dianalisis untuk kemudian dihasilkan suatu gambaran dan solusi yang komprehensif mengenai penerapan kebijakan sistem zonasi.

Rumusan masalah dalam tulisan ini adalah komunikasi kebijakan pemerintah yang kurang tersampaikan dengan baik terhadap mayoritas pemangku kepentingan pendidikan dan berbagai hambatan operasional dari kebijakan umum sehingga menuai pro dan kontra. Studi ini bertujuan untuk mengkaji dan membahas secara menyeluruh mengenai sejarah penerapan sistem zonasi global, tujuan penerapan sistem zonasi, keuntungan dan tantangan serta solusi mengatasi tantangan penerapan sistem zonasi. Hasil kajian diharapkan mampu memberikan bahan evaluasi dan perbaikan yang lebih baik dari penerapan sistem zonasi, khususnya terkait masalah komunikasi kepada mayoritas pemangku kepentingan pendidikan dan hambatan operasional kebijakan umum sistem zonasi.

Metode yang digunakan dalam penelitian ini adalah narrative review, dengan menghimpun berbagai sumber dan data terkait topik penelitian (Wiles, Crow \& Pain, 2011). Adapun sumber yang digunakan adalah jurnal terdahulu berskala nasional dan internasional dan berita-berita di media yang menyajikan data atau pemaparan terkait program zonasi. Data-data jurnalistik juga turut dianalisis, karena kebaruan dari fenomena pro dan kontra sistem zonasi direkam secara relatif lebih cepat dan lengkap, meski dalam fragmen-fragmen di media ketimbang dalam publikasi ilmiah. Literatur yang telah diidentifikasi itu kemudian dikumpulkan dan dianalisis untuk memunculkan tema-tema yang dominan dan berkaitan. Penyajian data kemudian dilakukan secara naratif, membentuk suatu kesatuan informasi yang dapat menunjukkan aspek kunci dari topik pembahasan sekaligus aspek historis yang penting untuk memahami kausalitas suatu kebijakan.

Metode pengkajian naratif ini menawarkan solusi yang memperhatikan seluruh elemen yang membangun narasi. Adapun kelemahan penelitian ini adalah kecenderungan yang mungkin dihasilkan dari narasi yang dominan yang muncul dalam literatur yang diteliti (Ferrari, 2015). Untuk itu akan dipertimbangkan semua narasi minor yang mungkin muncul dalam literatur sebagai wacana alternatif yang menyeimbangkan tema-tema dominan.

\section{KAJIAN LITERATUR \& PEMBAHASAN}

\section{Sistem Zonasi dan Sejarahnya}

Penerapan sistem zonasi di Indonesia salah satunya juga terinspirasi oleh negara-negara lain yang terlebih dahulu menerapkannya. Pada tahun 1940-an prinsip perekrutan siswa berdasarkan letak geografis telah diaplikasikan di negara-negara Eropa (Coughlan, 2018). Negara-negara di Eropa menganggap bahwa kompetisi pasar di dunia pendidikan menyebabkan persaingan yang tidak sehat antara sekolah; membangun kasta-kasta bagi sekolah, dan memperburuk situasi sekolah yang sejak awal tidak memiliki sumber daya yang cukup untuk mengejar ketertinggalan. Parahnya, korban dari kompetisi itu adalah anak-anak dari keluarga kelas bawah, sebab mereka tidak dapat menikmati akses pendidikan yang layak (Coughlan, 2018). Dalam situasi tersebut kebijakan zonasi dipertimbangkan agar terjadi pemerataan pendidikan sehingga semua kelas sosial memiliki kesempatan yang sama dalam mengenyam pendidikan berkualitas.

Tidak hanya di Eropa, penerapan sistem zonasi di dunia pendidikan juga diterapkan di Amerika dan Asia (Põder, Lauri \& Veski, 2016; 
Akabayashi \& Araki, 2011). Sistem zonasi banyak diterapkan dikarenakan kemampuannya untuk secara objektif meningkatkan pemerataan pendidikan di negara-negara tersebut. Begitu pula di Indonesia, zonasi diharapkan dapat mengatasi kesenjangan akses dan kualitas pendidikan di berbagai daerah (Kementerian Komunikasi dan Informatika, 2019). Argumentasi untuk penerapan sistem zonasi seringkali merujuk kepada fenomena kesuksesan di negara-negara maju di atas (Wahyuni, 2018). Meski, yang sering terlewat adalah bahwa kondisi dalam penerapan kebijakan tidak bisa dipisahkan dari konteks kebijakan lain yang lebih luas.

Faktanya, sistem zonasi yang berkembang di negara-negara itu tidak berjalan sendirian. Bersamaan dengan perubahan yang radikal atas sistem penerimaan siswa, negara-negara itu juga mengakselerasi peningkatan kapasitas guru dan pemenuhan fasilitas di institusi pendidikan (Cheng, 2020; Coughlan, 2018). Pemerintah juga mendorong kompetisi di antara pendidikan publik dan swasta agar sekolah-sekolah terus berinovasi dalam mengembangkan diri (Lakes \& Carter, 2011). Di Finlandia, misalnya, setiap sekolah bahkan memiliki keleluasan untuk bereksperimen dengan metode pembelajaran dan tidak adanya standarisasi nilai yang ketat di antara semua satuan pendidikan (Põder, et al., 2016). Kebijakan reformasi pendidikan yang lain yang mendampingi sistem zonasi di Indonesia barangkali belum banyak diketahui oleh masyarakat sehingga sistem zonasi sebagai pembatasan hak kiranya sebagai bagian dari kombinasi kebijakan pendidikan yang lebih besar.

Tujuan lain dari penerapan sistem zonasi yang ditetapkan oleh pemerintah di negaranegara maju agar setiap sekolah dan wali murid terlibat dalam perencanaan. untuk membantu sekolah mempertahankan struktur pengajaran yang stabil, untuk pemerataan sekolah sehingga setara, untuk menertibkan penggunaan sumber daya nasional seperti perencanaan, pembangunan, dan mencegah terjadinya fluktuasi penutupan sekolah karena adanya masalah kepegawaian (Coughlan, 2018). Lebih jauh, reformasi yang terjadi biasanya bersamaan dengan reorientasi visi pendidikan nasional dan reorganisasi pendidikan dalam berbagai tingkatan (Cheng, 2020). Sebagaimana kasus yang terjadi di negara-negara yang menerapkan zonasi, penerimaan dari masyarakat atas sistem ini membutuhkan waktu, terutama di negara yang memang sejak lama telah memberlakukan 'kebebasan dan kompetisi' dalam memilih sekolah (Lakes \& Carter, 2011).

\section{Argumen Penerapan Zonasi: Mendorong Pemerataan Kualitas Pendidikan}

Pemerintah menerapkan sistem zonasi dengan penuh pertimbangan terkait manfaat dan konsekuensinya. Menurut Safitri (2019) menteri pendidikan menyatakan bahwa setiap anak bangsa memiliki hak yang sama atas layanan pendidikan yang berkualitas sehingga tidak terjadi diskriminasi, eksklusivisme, dan kompetisi yang berlebihan untuk mendapatkan layanan pemerintah. Sekolah negeri selaku layanan publik harus mampu menciptakan pendidikan dengan nilai-nilai ideal di atas (Locatelli, 2018). Untuk mencapai tujuan pendidikan tersebut, instansi atau sekolah-sekolah harus memiliki ciri universalitas, yaitu semua kalangan harus bisa mengaksesnya (non excludable), tidak adanya persaingan yang ketat (non rivalry), dan tidak ada diskriminasi (non discrimination) (Coughlan, 2018; Daviet, 2016; Locatelli, 2018).

Tercapainya tujuan sekolah zonasi, tidak hanya untuk layanan akses pendidikan yang merata, lebih jauh adalah agar pencapaian prestasi akademik siswa yang optimal sebagai produk dari hasil pendidikan. MeenuDev (2016) menyebutkan pencapaian akademik siswa adalah hasil yang diperoleh siswa atas usahanya menghadapi berbagai faktor yang menjadi penghambat dan tantangan kinerja akademik yang optimal. Kinerja akademik didefinisikan sebagai hasil atau produk dari proses pendidikan 
Nandy Agustin Syakarofath, Ahmad Sulaiman, \& Muhamad Faqih Irsyad, Kajian Pro Kontra Penerapan Sistem Zonasi Pendidikan di Indonesia

dan mengukur sejauh mana siswa, guru, dan lembaga pendidikan telah mencapai tujuan pendidikan (Mary \& Jeba Seelan, 2014).

Sebagai kebijakan reformatif, sistem zonasi sejatinya telah memiliki analisis yang radikal dan objektif terhadap permasalahan dan kondisi pendidikan di Indonesa. Pada sistem zonasi terdapat dua faktor utama yang dapat memengaruhi prestasi akademik siswa sebagai produk akhir proses pendidikan yaitu karakteristik atau latar belakang keluarga siswa dan lingkungan sekolah dan atau teman sebaya. Pada karakteristik atau latar belakang siswa meliputi beberapa aspek yaitu bahasa $\&$ sumber daya pendidikan di rumah, pendidikan orang tua, status sosial ekonomi (SES). Hal ini sejalan dengan pendapat Hanushek \& Woessmann, (2010) dan Jaiswal (2018) bahwa keluarga adalah faktor utama dalam proses pendidikan yang dianggap memiliki pengaruh yang kuat.

Pada sistem zonasi, partisipasi keluarga atau orangtua harus ditingkatkan untuk mendorong pembelajaran siswa di rumah yang integral dengan pendidikan di sekolah (Bintoro, 2018). Pendidikan yang bersifat parsial atau sekedar tanggungjawab guru sudah tidak ada lagi. Apalagi mengingat visi utama pendidikan Indonesia yang sudah diarahkan kepada pembentukan karakter di samping mengasah nalar dan pengetahuan siswa. Peran atau keterlibatan orangtua akan sangat dibutuhkan. Sistem zonasi akan membantu mendekatkan orangtua dengan sekolah dan dengan demikian mendorong tercapainya misi untuk semakin melibatkan orangtua dalam proses pendidikan anak mereka.

Pada lingkungan sekolah dan teman sebaya terdapat aspek kualitas guru atau tenaga pengajar, kepemilikan lembaga, dan modal sosial masyarakat. Mendukung pernyataan tersebut menyebutkan lingkungan sekolah dan teman sebaya memengaruhi kinerja akademik siswa (Korir \& Kipkemboi, 2014; Okafor, Maina, Stephen, \& Ohambele, 2016; Olayemi, 2018;
Moldes, Biton, Gonzaga, \& Moneva, 2019). Lingkungan sekolah dan teman sebaya membantu siswa untuk tumbuh lebih baik secara sosial sehingga empati dan motivasi belajar menjadi lebih tinggi. Sistem zonasi mendorong pemerataan siswa berprestasi sehingga dapat menciptakan lingkungan sekolah atau teman sebaya yang lebih merata di semua sekolah (Nabaiho, 2018; Bintoro, 2018; Purwati, Irawati, \& Adiwisastra, 2018).

Interaksi dari kedua faktor tersebut melalui sebuah sistem pendidikan dianggap sangat berkontribusi untuk mendorong siswa agar dapat optimal dalam meraih prestasi akademik. Karakteristik atau latar belakang keluarga, lingkungan sekolah, serta teman sebaya dalam memengaruhi prestasi akademik siswa dapat dilihat pada Bagan 1.

Dengan demikian, penerapan sistem zonasi telah berusaha mengatasi dua permasalahan sekaligus. Pertama, permasalahan pemerataan kualitas pendidikan. Kedua, permasalahan partisipasi orang tua atau keluarga dalam proses pendidikan anak. Bagaimana kemampuan sistem zonasi dalam memecahkan kedua persoalan di atas telah diuji dalam penerapannya sebagaimana akan diungkap pada berikut ini.

\section{Penerapan Sistem Zonasi}

Berdasarkan Permendikbud Nomor 14 Tahun 2018, penerimaan peserta didik yang sebelumnya melalui kompetisi dengan nilai ujian menjadi penerimaan yang didasarkan pada: 1 ) jarak tempat tinggal ke sekolah sesuai zona, 2) Surat Hasil Ujian Nasional (bagi lulusan SMP); dan 3) prestasi akademik dan nonakademik. Kebijakan ini berlaku di semua sekolah pemerintah daerah. Adapun jumlah siswa yang diterima menurut zonasi adalah sembilanpuluh persen, jalur prestasi di luar zona 5 persen, dan perpindahan domisili atau terjadi bencana lima persen. Berdasarkan instruksi pemerintah kebijakan PPDB sistem zonasi di semua daerah didasarkan pada asas yang objektif, transparan, 


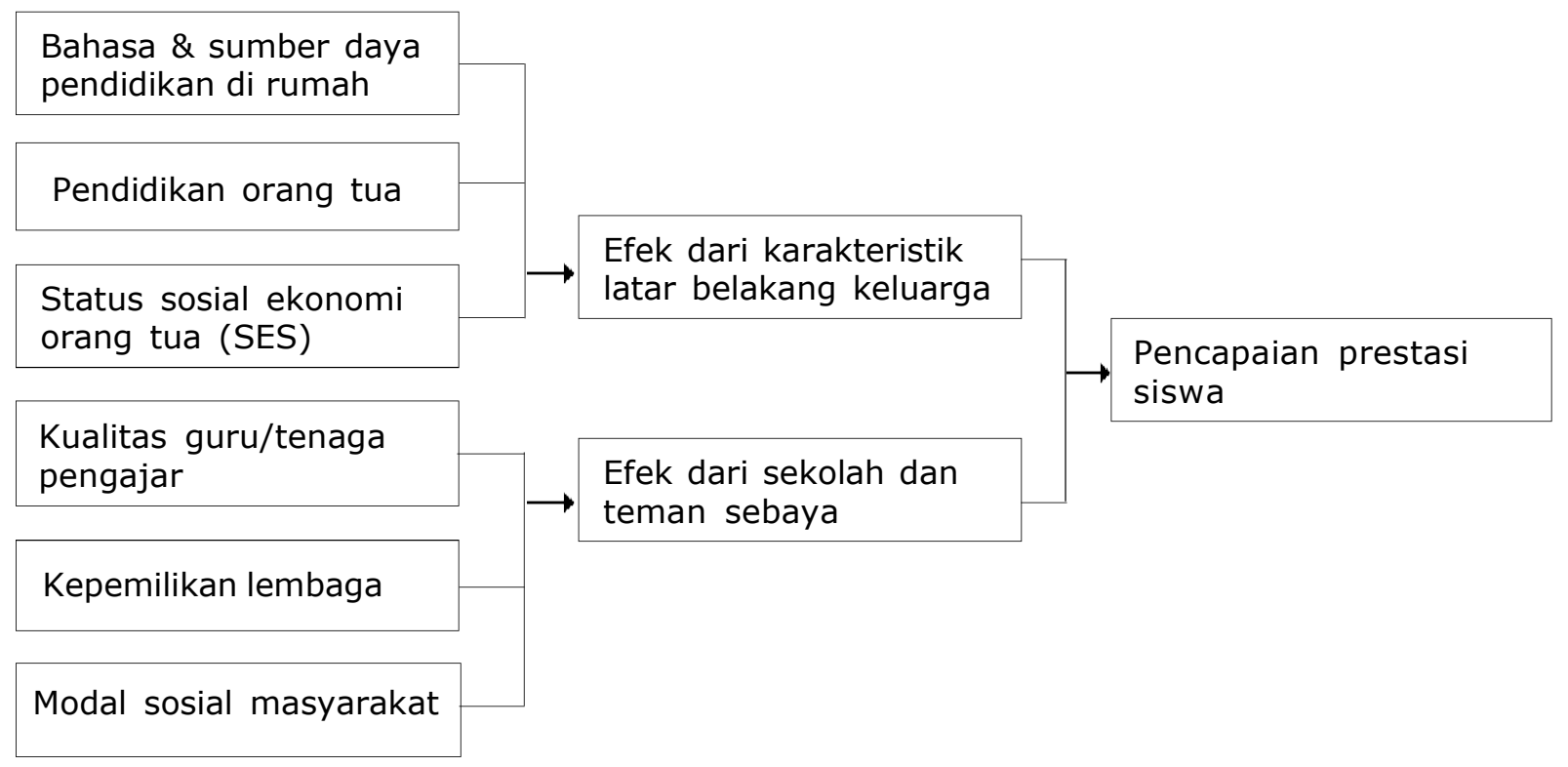

Bagan 1 Kerangka Konseptual Pendidikan oleh (Põder, et al., 2016)

akuntabel, dan berkeadilan (Purwati, et al., 2018).

\section{Keuntungan dan Tantangan}

PPDB mendapat respon positif dari beberapa kalangan karena kemampuannya untuk memberi akses yang lebih luas kepada siswa bertaraf ekonomi rendah (Dewi \& Septiana, 2018). Bagi siswa, kesulitan biaya ke bimbel dan mendapat nilai tinggi untuk masuk sekolah yang diinginkan sudah tidak menjadi rintangan. Tidak adanya kekhawatiran menempuh perjalanan jauh untuk dapat ke sekolah karena keterbatasan kepemilikan alat transportasi. Bahkan, jarak dari rumah ke sekolah dapat ditempuh hanya dengan berjalan kaki. Dalam hal ini, zonasi menunjukkan kapasitasnya untuk membantu mendorong akses siswa yang berasal dari kelas sosial rendah yang selama ini hanya kelas sosial menengah ke atas saja sebagaimana yang telah terjadi selama kurun waktu satu dekade terakhir (Martono, 2019).

Bagi orangtua, mereka merasa lebih tenang karena dapat lebih mudah dalam mengontrol anak anak mereka. Berkat zonasi, jarak antara rumah dan sekolah tidak lagi berjauhan (Dewi \& Septiana, 2018). Orang Tua dapat tiba ke sekolah dalam waktu yang relatif lebih singkat dibanding sebelumnya. Kedekatan jarak antara rumah dan sekolah dapat membuat orang tua lebih leluasa dan mudah dalam berkomunikasi dengan pihak sekolah secara langsung mengenai capaian pembelajaran anak-anak mereka.

Bagi sekolah, sistem zonasi membantu beberapa sekolah di daerah menjadi lebih berkembang karena mendapatkan kualitas siswa yang beragam (Bintoro, 2018). Hal ini membuat guru semakin termotivasi untuk meningkatkan kapasitas dirinya. Sekolah-sekolah yang dulunya memiliki label sekolah nonfavorit, sekarang memiliki kesempatan yang sama untuk menerima siswa yang nilainya di atas rata-rata. Input siswa yang lebih baik itu dapat dikapitalisasi untuk menghasilkan prestasi yang lebih baik yang kemudian dapat meningkatkan atau mengubah reputasi sekolah (Dewi \& Septiana, 2018). Memperhatikan respon-respon dan dampak positif dari dan kepada masyarakat tersebut, maka sistem zonasi dianggap sudah tepat diimplementasikan bagi beberapa pengamat dan peneliti kebijakan pendidikan (Nabaiho, 2018; Bintoro, 2018; Purwati, et al, 2018). 
Nandy Agustin Syakarofath, Ahmad Sulaiman, \& Muhamad Faqih Irsyad, Kajian Pro Kontra Penerapan Sistem Zonasi Pendidikan di Indonesia

Namun, selain respon positif di atas, muncul pula tanggapan negatif dari banyak pihak. Berdasarkan evaluasi, penerimaan PPDB 2019 yang dijalankan pemerintah secara serentak di tingkat SMP dan SMA menuai bermacam kritik di kalangan masyarakat. Pertama, masyarakat menilai bahwa sistem zonasi justru tidak mampu menyelesaikan isu pendidikan yang substansial dan fundamental karena tidak semua kualitas sekolah dan pengajarnya setara di semua daerah (Wahyuni, 2018). Banyak sekolah yang lokasinya terkonsentrasi di suatu zona di daerah sehingga menyulitkan masyarakat yang tinggal di pinggiran atau di zona lain (Chen, 2011), serta infrastruktur Indonesia dinilai belum merata menjangkau daerah-daerah di luar pulau jawa (Kusharjanto \& Kim, 2011). Alhasil pelaksanaan sistem zonasi yang tergolong baru dirasakan malah hanya menambah sulit bagi orangtua untuk menyekolahkan anaknya di sekolah dengan kualitas baik (Muammar, 2019). Idealnya, pemerintah menyiapkan terlebih dahulu sekolahsekolah dengan merata secara geografis dan kualitas, baru kemudian menerapkan sistem zonasi. Juga, kemungkinan polemik yang muncul seharusnya telah diduga jauh sebelum sistem zonasi diterapkan. Dari sisi kapasitas sekolah yang secara umum masih minim, dapat dikatakan bahwa sistem zonasi dianggap terlalu dini untuk diterapkan saat ini.

Penerapan jalur prestasi juga dirasa kurang tepat karena proporsi 5 sampai 10 persen dianggap terlalu kecil untuk dapat mewadahi banyaknya siswa berprestasi. Efeknya, sebagian masyarakat merasa "tercurangi" atas sistem zonasi, khususnya bagi mereka yang putraputrinya mendapat nilai ujian akhir yang tinggi. Mereka merasa capaian belajar anak-anak mereka menjadi tidak penting sebab sekolah hanya melihat siapa-siapa yang tinggal paling dekat dengan sekolah (Wahyuni, 2018). Banyak dari mereka yang putus asa dan marah karena nilai akademis yang diperoleh dari proses perjuangan dengan mengikuti program-program tambahan belajar (bimbel) kalah dengan mereka yang tinggal dekat sekolah padahal nilai akademisnya jauh lebih rendah (Apinino 2018, Setiawan 2019).

Jarak rumah ke sekolah sebagai penentu utama juga dipandang sulit diterapkan mengingat distribusi keberadaan sekolah dan jumlah penduduk kurang merata. Hal ini berdampak terhadap sebaran siswa di setiap sekolah-sekolah. Lebih jauh dari itu, kondisi tersebut menyebabkan ada sekolah yang kelebihan siswa dan ada sekolah yang kekurangan siswa (Apinino 2018, Adji 2019). Misalnya yang terjadi di SMPN 1 Balongan di Indramayu yang kelebihan 60 siswa, dan SMPN 2 Balongan yang kekurangan siswa (Adji 2019). Masalah kekurangan siswa di zonasi bukan padat penduduk akan berdampak pada jumlah jam mengajar guru. Ini tentu akan merugikan mereka dalam hal pengurusan tunjangan sertifikasi (Apinino 2018). Adji (2019) menambahkan bahwa polemik kekurangan dan kelebihan siswa ternyata juga berdampak pada sekolah-sekolah swasta yang berlokasi di pusat kota. Mereka mesti bersaing dengan sekolah-sekolah negeri yang umumnya menjamur di zona pusat kota.

Penerapan sistem zonasi juga dinodai dengan munculnya pelanggaran-pelanggaran dalam pelaksanaan sistem zonasi. Dalam aturan yang berlaku, penentuan jarak tempat tinggal ke sekolah dilihat dari jarak RW alamat tempat tinggal calon siswa sesuai yang tertera di Kartu Keluarga (KK) (Wahyuni, 2018). Hal ini meresahkan masyarakat karena berpeluang terjadinya kecurangan. Hal ini pun terbukti, telah terjadi penitipan nama siswa dalam KK milik anggota keluarga yang tinggal berdekatan dengan sekolah, hingga penjualan kursi oleh beberapa oknum. Misalnya, Federasi Serikat Guru Indonesia (FSGI) telah menemukan seorang siswa asal Cibinong, Bogor, menumpang nama di KK saudaranya di Kramat Jati, Jakarta Timur supaya bisa sekolah di daerah tersebut (Apinino 2018). 
Selain dugaan manipulasi melalui KK, muncul juga dugaan pelanggaran pada jalur Surat Keterangan Tidak Mampu (SKTM) dan jalur pindah domisili bagi orangtua yang dipindahtugaskan pekerjaan. Kebijakan ini dianggap menimbulkan berbagai kecurigaan masyarakat atas peluang tindakan yang tidak terpuji yang dapat dilakukan oleh orang tua agar anaknya dapat mengenyam pendidikan di tempat yang diinginkan meskipun berada di luar zona (Wahyuni, 2018). Kuota sebanyak 20 persen pernah dianggap menjadi peluang, karena berdasarkan laporan dari beberapa sekolah bahwa jumlah tersebut tidak terpenuhi (Bakar, Supriyati \& Hanafi, 2019).

Satriawan Salim, Wasekjen FSGI, mengungkap bahwa jalur SKTM mengada-ngada. Menurutnya, pada pasal 16 ayat 1 sampai 6 Permendikbud Nomor 14 Tahun 2018 tentang PPDB tidak ada istilah SKTM yang terkait dengan jalur penerimaan dalam sistem zonasi (Apinino 2018). Walaupun sebetulnya masih diperdebatkan, banyak ditemukan sekolah yang membuka jalur SKTM. Akhirnya kekhawatiran mengenai kecurangan yang ditimbulkan oleh jalur SKTM ini terbukti. Misalnya, di berbagai daerah begitu banyak SKTM palsu ditemukan pada proses penerimaan peserta didik baru. Misalnya, di tingkat SMAN dan SMKN di Jawa Tengah, setidaknya terdapat 78.065 SKTM yang dicoret dan dibatalkan (Nurdin 2018). Nurdin (2018) menambahkan dari 221.785 total kursi, hampir 150.000 atau lebih dari separuh calon siswa baru mendaftarkan diri dengan melampirkan SKTM.

Melihat berbagai masalah dan fakta bahwa sistem zonasi merupakan suatu kebijakan yang baru, sebetulnya kita mesti maklum bila pelanggaran telah terjadi begitu masif. Hanya saja yang paling berbahaya adalah kondisi ini bisa menimbulkan ketidakpercayaan masyarakat pada sekolah dan pemerintah. Mengingat pendidikan merupakan kunci untuk mobilitas sosial dan karenanya merupakan hal yang sangat penting bagi masyarakat. Kegagalan pemerintah dalam mengantisipasi permasalahan yang timbul oleh zonasi akan membuat kekecewaan masyarakat yang sangat besar.

Permasalahan pokok dari penerapan sistem zonasi adalah kesiapan yang kurang dari berbagai elemen utama seperti siswa, orangtua, dan sekolah (readiness for change). Semestinya, sistem yang dibuat pemerintah sejalan dengan kesiapan semua pemangku kepentingan pendidikan, seperti tim manajemen sekolah, Kementerian Pendidikan dan Kebudayaan sebagai penyelenggara, serta orang tua dan calon siswa baru yang akan terdampak. Faktanya, masih adanya kesenjangan kualitas sarana dan prasarana serta tenaga pendidik di antara sekolah yang berada di perkotaan dan di daerah (Kabupaten) (OECD/Asian Development Bank, 2015; Vito, Krisnani, \& Risna, 2015). Literasi dan pemahaman siswa, orang tua, dan penyelenggara pendidikan masih minim tentang sistem zonasi (Oktaviari, 2020). Akibatnya timbul mispersepsi di tengah masyarakat seperti tidak mungkin mendaftarkan anak ke sekolah favorit di luar zona (Bintoro, 2018; Safarah \& Wibowo, 2018), atau kekhawatiran sekolah bahwa reputasi mereka akan turun dengan menerima siswa yang memiliki nilai rendah dikarenakan zonasi (RRI, 2019).

Persepsi masyarakat mengenai dampak dari sistem zonasi, secara umum dapat kita simpulkan dua hal. Pertama, pihak yang pro terhadap implementasi sistem zonasi dari sisi kebermanfaatan objektif program tersebut, yaitu pemerataan kualitas akses pendidikan (Safarah \& Wibowo, 2018; Wahyuni, 2018). Peningkatan pemerataan akses pendidikan itu dapat dilihat dari penghapusan stigma sekolah favorit dan tidak favorit, mengurangi jarak tempuh siswa dari rumah ke sekolah, dan mendistribusikan siswa-siswa dari berbagai latar belakang dan capaian pembelajaran secara lebih merata.

Kedua, pihak yang kontra tampaknya lebih melihat kelemahan sistem zonasi dari aspek 
Nandy Agustin Syakarofath, Ahmad Sulaiman, \& Muhamad Faqih Irsyad, Kajian Pro Kontra Penerapan Sistem Zonasi Pendidikan di Indonesia

kesiapan pelaksanaan teknis yang kurang optimal (Arnani, 2019). Kelemahan teknis penerapan sistem zonasi menyebabkan efek samping seperti kekecewaan yang besar karena keinginan untuk masuk di sekolah yang dianggap favorit tidak tercapai karena berasal dari luar zona. Sekolah yang awalnya menjadi tujuan utama anak-anak memilih sekolah sebab label favoritnya saat ini peminatnya berkurang, bahkan di beberapa sekolah kuota pendaftar tidak terpenuhi mengingat jumlah siswa yang berada di dalam zona sedikit. Pada dasarnya, baik yang pro maupun yang kontra memiliki alasan tersendiri berdasarkan sudut pandang pribadinya sehingga memiliki perspektif yang berbeda. Apapun persepsi yang dimiliki masyarakat saat ini, kondisi riil yang harus dihadapi adalah mengikuti regulasi dan kebijakan yang telah ditetapkan oleh pemerintah baik bagi yang pro maupun yang kontra terlepas dari sikapnya terhadap kebijakan tersebut.

Namun demikian, pekerjaan rumah terbesar pemerintah adalah mempersiapkan fasilitas yang menunjang sistem zonasi itu. Sebagaimana diungkap oleh Satriawan Salim, Waksekjen FSGI, bahwa "jangka panjang PPDB akan adaptif dan implementatif jika pemerintah memaksimalkan sarana dan prasarana sekolah" (Arnani, 2019). Dengan demikian, tujuan paripurna dari penerapan zonasi yaitu menciptakan pendidikan nasional yang berasas kemajuan juga keadilan akan benar-benar tercapai (Permendikbud Nomor 44 Tahun 2019).

\section{Solusi yang Ditawarkan}

Sebagai suatu kebijakan yang relatif baru diterapkan tujuan utama sistem zonasi tidak langsung bisa terwujud secara optimal. Banyak kendala dan tantangan yang dihadapi agar terlaksana dengan baik. Masalah utama dari penerapan sistem zonasi adalah komunikasi kebijakan yang kurang direspon positif oleh mayoritas pemangku kepentingan pendidikan serta masalah teknis atau operasional dari kebijakan umum yang dibuat oleh kemendikbud dan diturunkan dalam peraturan-peraturan PSBB yang bersifat lokal di setiap daerah.

Kebijakan publik dan pelaksanaan birokrasi merupakan dua elemen penting dalam mewujudkan cita-cita pendidikan. Pada umumnya implementasi kebijakan mengacu pada sistem pengelolaan urusan publik (administrative governance). Agar pengelolaan urusan publik ideal (good governance), perlu diadakan reformasi birokrasi di lembaga pendidikan. Hal tersebut mencakup beberapa tindakan untuk meminimalisir munculnya ketidaksetujuan (kontra) dari kalangan masyarakat sebagai subjek yang terdampak.

Dalam tulisan ini ditawarkan solusi pemecahan masalah zonasi melalui tiga strategi implementasi program zonasi agar mencapai kondisi yang ideal. Strategi pertama yaitu penerjemahan tujuan dan sasaran kebijakan agar sesuai dengan kondisi lokasi dari penerapan sistem tersebut (Khan, 2016). Jika dikemudian hari ditemukan ketidaksesuaian, pemerintah harus mengidentifikasi berbagai tindakan sebagai alternatif solusi yang bisa ditawarkan. Oleh karenanya, pemerintah perlu melakukan identifikasi awal kebutuhannya dan persiapan agar di kemudian hari berjalan sebagaimana mestinya, mengingat setiap kebijakan pasti bersinggungan langsung dengan hajat hidup orang banyak. Perlu kehati-hatian, kepekaan dan sikap empati yang tinggi dari pemangku kebijakan dalam menetapkan kebijakan publik (Taufiqurokhman, 2014).

Wacana baru dari kemendikbud yang ingin memberi porsi lebih untuk peserta didik berprestasi dan memberi ruang bagi pemerintah daerah dalam menetapkan ukuran dari porsi jalur prestasi adalah satu langkah awal yang patut diapresiasi. Meski demikian, diperlukan langkahlangkah lain seperti mempertimbangkan akselerasi pembangunan sekolah-sekolah baru karena banyak calon peserta didik berada di daerah terjauh dari zona-zona yang telah 
ditetapkan. Bahkan calon peserta didik tersebut berada di daerah terpinggir dari pusat kota, namun mereka tetap bagian dari warga negara Indonesia yang berhak mendapatkan pendidikan. Negara melalui sekolah-sekolah yang ada juga perlu mempertimbangkan membuat kelaskelas tambahan dalam wujud daring untuk mengakomodasi peserta didik dari kelas sosial menengah ke bawah yang masih tidak mendapat kesempatan untuk belajar di sekolah negeri dikarenakan lokasi tempat tinggal yang berada di luar zonasi.

Kedua, mempersiapkan masyarakat terdampak terhadap kebijakan baru agar dapat terbuka, mengapresiasi dan turut berpartisipasi mensukseskan program ini melalui penyebaran informasi yang akurat mengenai sistem zonasi. Pro dan kontra yang dilontarkan masyarakat atas penerapan kebijakan baru adalah hal yang lumrah dikarenakan minimnya pengetahuan terkait manfaat untuk peserta didik. Oleh karena itu, masyarakat terdampak dari kebijakan tersebut perlu dipersiapkan, salah satu caranya adalah dengan meningkatkan literasi dan pengetahuan masyarakat melalui sosialisasi agar masyarakat mendapatkan pemahaman yang menyeluruh (Luangsithideth, Huda, Supriyanto, Wiyono, 2017). Upaya meningkatkan pemahaman masyarakat terkait program zonasi melalui literasi adalah sekumpulan proses yang harus dilalui agar diseminasi berhasil. Tujuannya adalah agar masyarakat memperoleh informasi yang tepat, timbul kesadaran di dalam dirinya sehingga mau menerima, dan akhirnya memanfaatkan informasi tersebut untuk mensukseskan kebijakan zonasi yang ditetapkan pemerintah.

Pemanfaatan informasi dapat dilakukan dengan memanfaatkan lebih optimal mediamedia baik televisi maupun daring. Kerja sama dapat dilakukan dengan tokoh-tokoh publik yang memiliki pengaruh besar di media sosial agar secara langsung dan masif membagikan informasi mengenai tujuan fundamental dari sistem zonasi. Pembangunan kesadaran mengenai tujuan sistem zonasi juga sangat penting sehingga terbentuk dukungan yang solid dari masyarakat atas kebijakan baru. Hal tersebut yang mengubah secara drastis sistem kompetisi-eliminasi PSBB yang sebelumnya terlanjur mengakar kuat dalam tradisi pendidikan di Indonesia.

Ketiga, Luangsithideth, Huda, Supriyanto \& Wiyono (2017) memaparkan bahwa perlu dilakukan pemantauan dan evaluasi pelaksanaan secara komprehensif. Namun, pemantauan sistem zonasi dipandang memerlukan partisipasi dari masyarakat bukan sekedar kontrol dari negara saja. Misalkan, masyarakat perlu didorong untuk membantu dalam mengidentifikasi hal-hal yang perlu dibangun sekolah dan zona pendidikan baru. Hal ini penting dilakukan karena derasnya arus migrasi sementara belum adanya sistem yang baik dan terintegrasi baik antara pusat dan daerah maupun daerah-daerah menjadikan sulit bagi pemerintah untuk bekerja membangun zonazona pendidikan baru.

Untuk itu, tulisan ini menganggap perlu suatu proses evaluasi yang dilakukan secara berlapis-lapis. Evaluasi ini dapat dilakukan dengan cara sistematis oleh penyelenggara kebijakan (pemerintah), evaluasi yang dilakukan oleh pelaksana sistem di lapangan (sekolah), evaluasi yang dilakukan oleh ahli kepada masyarakat terdampak dan evaluasi dari masyarakat sendiri melalui komunitas, kelompok, atau bahkan dewan perwakilan (masyarakat). Integrasi dari beragam perspektif evaluasi ini diharapkan dapat memberikan gambaran yang komprehensif mengenai permasalahan penerapan sistem zonasi berdasarkan data riil di lapangan.

\section{SIMPULAN DAN SARAN \\ Simpulan}

Sistem zonasi tidak hanya diterapkan di Indonesia tetapi juga sudah diterapkan di beberapa negara lainnya. Meskipun terdapat keuntungan, juga terdapat tantangan sehingga 
Nandy Agustin Syakarofath, Ahmad Sulaiman, \& Muhamad Faqih Irsyad, Kajian Pro Kontra Penerapan Sistem Zonasi Pendidikan di Indonesia

menuai pro kontra di kalangan masyarakat. Pihak yang pro fokus kepada keuntungan-keuntungan atau manfaat dari sistem zonasi yaitu, terciptanya pemerataan akses layanan dan kualitas pendidikan yang lebih baik. Sekolah semakin berkembang dan maju karena mendapatkan input siswa yang lebih beragam begitu juga dengan kapasitas gurunya.

Selanjutnya, pihak yang kontra fokus pada kekurangan dari implementasi sistem zonasi yang kurang optimal. Kekurangan tersebut berupa kesiapan sekolah-sekolah di daerah seperti sarana dan prasarana serta kualitas pendidik yang belum setara, masalah kebijakan jalur prestasi yang dianggap belum mewadahi kebutuhan di lapangan, masalah penentuan jarak sekolah dan tempat tinggal yang menyebabkan sebaran jumlah peserta didik pada setiap sekolah menjadi tidak seimbang dan minimnya partisipasi aktif orangtua karena lemahnya literasi terkait sistem zonasi yang disebabkan oleh efek samping kelemahan teknis di lapangan.

Solusi untuk menjawab tantangan tersebut di antaranya, pertama menerjemahkan tujuan dan sasaran kebijakan agar sesuai dengan kondisi lokasi dari penerapan sistem zonasi. Kedua, mengkomunikasikan kebijakan zonasi secara akurat terutama kepada masyarakat sehingga masyarakat dapat mengapresiasi dan turut berpartisipasi mensukseskan program ini. Ketiga, pemantauan dan evaluasi secara berkala dan komprehensif yang melibatkan partisipasi masyarakat agar dapat mengidentifikasi hal-hal yang perlu dibangun atau diperbaiki dari sistem zonasi. Dari hasil kajian yang dilakukan, berbagai evaluasi yang diperoleh dapat dijadikan sebagai bahan pertimbangan pemerintah guna optimalisasi program yang lebih baik.

\section{Saran}

Pemerintah pusat disarankan mensinergikan kebijakan pembangunan di semua lini dengan sistem zonasi. Hal itu dapat dilakukan dengan mengkoordinasikan tiga kementerian, yaitu
Kementerian Pendidikan dan Kebudayaan (Kemendikbud), Kementerian Pekerjaan Umum dan Pekerjaan Rakyat (PUPR) dan Kementerian Perhubungan (Kemenhub). Ketiga kementerian itu disarankan merancang langkah strategis kolektif untuk mengakselerasi pembangunan sekolah-sekolah dan jalan-jalan sesuai dengan kondisi daerah mengingat aksesibilitas, sarana dan prasarana merupakan salah satu elemen penting optimalnya penerapan sistem zonasi.

Kemendikbud disarankan perlu mengkaji ulang sistem zonasi sebagai kebijakan nasional dan kaitannya dengan penerapan di tingkat lokal. Pemerintah daerah seringkali mengalami kesulitan dalam menerjemahkan kebijakan umum sehingga implementasi kebijakan terkadang berbeda-beda di tiap daerah, contoh proporsi kuota jalur prestasi dan pindahan luar domisili. Kemendikbud dapat mengurangi rentang proporsi kuota yang diatur dalam kebijakan nasional sistem zonasi agar perbedaan di antara daerah tidak terlalu tajam.

Sebagai konsekuensi dari saran di atas, Kemendikbud perlu melakukan revisi atas Permendikbud nomor 44 Tahun 2019, terkhusus Bab II pasal 11 yang mengatur proporsi dari jalur afirmasi, pindah domisili, dan jalur prestasi yang menjadi kewenangan pemerintah daerah. Revisi itu perlu melibatkan pihak-pihak seperti asosiasi-asosiasi profesi, anggota legislatif di tingkat daerah, serta pimpinan sekolah yang nantinya menjadi pelaksana penerimaan siswa melalui sistem zonasi.

Kemendikbud perlu mengedukasi masyarakat mengenai kebijakan sistem zonasi dalam rentang waktu yang lebih lama dan intensif melalui media sosial. Kampanye kebijakan dapat dilakukan sejak masa PPDB tahun sebelumnya agar masyarakat telah bersiap lebih dini. Penggunaan media-media kreatif seperti video singkat di media sosial untuk memvisualisasikan kebijakan sistem zonasi yang diberlakukan akan membantu menyederhanakan informasi yang cukup banyak dan baru kepada masyarakat luas. 


\section{PUSTAKA ACUAN}

Aritonang, A.I. (2011). Kebijakan komunikasi di Indonesia: Gambaran Implementasi UU.No. 14 Tahun 2008 Tentang Keterbukaan Informasi Publik. Jurnal Komunikasi, 1(3), 261-286. http://dx.doi.org/10.24329/aspikom.v1i3.24.

Aminudin, M. (2019). Kisruh zonasi penerimaan siswa baru, DPRD Malang protes Kemendikbud. https://news.detik.com/berita-jawa-timur/d-4563732/kisruh-zonasi-penerimaan-siswabaru-dprd-malang-protes-kemendikbud, 261-286.

Akabayashi, H., \& Araki, H. (2011). Do education vouchers prevent dropout at private high schools? Evidence from Japanese policy changes. Journal of the Japanese and International Economies, 25(3),183-198. https://doi.org/10.1016/j.jjie.2011.07.003.

Apinino, R. (2018). Empat kelemahan sistem zonasi dalam PPDB 2018. https://tirto.id/empatkelemahan-sistem-zonasi-dalam-ppdb-2018-cNP9.

Adji, B. (2019). Sistem zonasi sekolah: Distribusi siswa tak merata. https:// nasional.republika.co.id/berita/nasional/umum/ptnzjc440/sistem-zonasi-sekolah-distribusisiswa-tak-merata.

Arnani, M. (2019). Polemik sistem zonasi penerimaan murid baru, ini kata federasi guru. https:/ /edukasi.kompas.com/read/2019/06/19/14080321/polemik-sistem-zonasi-penerimaanmurid-baru-ini-kata-federasi-guru?page=all.

Bakar, K.A.A., Supriyati, Y., \& Hanafi, I. (2019). The evaluation of admission student policy based on zoning sys-tem for acceleration education quality in Indonesia. Journal of Management Info, 6(2), 19-24.

Bintoro, R.F.A., (2018). Persepsi masyarakat terhadap implementasi kebijakan zonasi sekolah dalam penerimaan peserta didik baru (PPDB) tingkat SMA tahun ajaran 2017/2018 di kota Samarinda. Jurnal Riset Pembangunan, 1 (1), 48-57. https://doi.org/10.36087/jrp.v1i1.26

Chen, D. (2011). School-based management, school decision-making and education outcomes in Indonesian primary schools. The World Bank.

Cheng, Y.C. (2020). Education reform phenomenon: A typology of multiple dilemmas. In Handbook of Education Policy Studies (pp. 85-109). Springer, Singapore.

Coughlan, R.W. (2018). Divergent trends in neighborhood and school segregation in the age of school choice. Peabody Journal of Education, 93(4), 349-366. https://doi.org/10.1080/ 0161956 X.2018.1488385.

Dewi, K.E \& Septiana, R. (2018). Evaluation of zoning student recruitment system in year 2018. Proceeding International Seminar on Education: Innovation Issues and Challenges in Education for Education Sustainability. Universitas Sarjanawiyata Tamansiswa. http:// jurnal.ustjogja.ac.id/index.php/dpsp2018/ article/view/3234. (accessed, 19 August 2019)

Daviet, B. (2016). Revisiting the principle of education as a public good. In education research and foresight.

Kementerian Komunikasi dan Informatika. (2019). Semua bisa sekolah. Zonasi untuk pemerataan yang berkualitas. https://www.kominfo.go.id/content/detail/13689/semua-bisa-sekolahzonasi-untuk-pemerataan-yang-berkualitas/0/artikel_gpr.

Ferrari, R. (2015). Writing narrative style literature reviews. Medical Writing, 24(4), 230-235. https://doi.org/10.1179/2047480615Z.000000000329. 
Nandy Agustin Syakarofath, Ahmad Sulaiman, \& Muhamad Faqih Irsyad, Kajian Pro Kontra Penerapan Sistem Zonasi Pendidikan di Indonesia

Hanushek, E.A., \& Woessmann, L. (2010). The high cost of low educational performance: The long-run economic impact of improving PISA outcomes. In OECD Publishing. https:// doi.org/10.1787/9789264077485-en.

Hasanah, Y.M., \& Jabar, C.S.A. (2017). Evaluasi program wajib belajar 12 tahun pemerintah daerah Kota Yogyakarta. Jurnal Akuntabilitas Manajemen Pendidikan, 5(2), 228-239. https://doi.org/10.21831/amp.v5i2.8546.

Ismanto, B., Tagela, U., \& Wasitohadi. (2017). Kinerja pendidikan dasar dalam implementasi program pendidikan. Kelola: Jurnal Manajemen Pendidikan, 4(1), 1-11. https://doi.org/ 10.24246/j.jk.2017.v4.i1.p1-11.

Jaiswal, S.K. (2018). Influence of parent's education on parental academic involvement. Journal of Advances and Scholarly Researches in Allied Education, 15(5), 114-119. https:// doi.org/10.29070/15/57555.

Kusuma. (2019). Atas rekomendasi Ombudsman RI, zona PPDB SMA di Yogyakarta diperluas. https://yogyakarta.kompas.com/read/2019/06/13/12061131/atas-rekomendasiombudsman-ri-zona-ppdb-sma-di-yogyakarta-diperluas (accessed, 1 August 2019).

Kusharjanto, H. \& Kim, D. (2011). Infrastructure and human development: The case of Java, Indonesia. Journal of the Asia Pacific Economy, 16(1), 111-124. https://doi.org/10.1080/ 13547860.2011 .539407

Korir, D.K., \& Kipkemboi, F. (2014). The impact of school environment and peer influences on students' academic performance in Vihiga County, Kenya. Journal of Education and Practice, 5(11), 1-11.

Khan, A.R. (2016). Policy implementation: some aspects and issues. Journal of Community Positive Practices, 16(3), 3-12.

Lakes, R.D., \& Carter, P.A. (2011). Neoliberalism and education: An introduction. Educational Studies, 47(2), 107-110. https://doi.org/10.1080/00131946.2011.556387.

Locatelli, R. (2018). Education as a public and common good: Reframing the governance of education in a changing context. In Educartion research and forsight.

Luangsithideth, V., Huda, M., Supriyanto, A., Wiyono, B.B. (2017). Policy implementation of improving education quality of primary education teachers in Laos and Indonesia. Asian Social Science, 13(3), 145-155. https://doi.org/10.5539/ass.v13n3p145.

Mandic, S., Sandretto, S., García Bengoechea, E., Hopkins, D., Moore, A., Rodda, J., \& Wilson, G. (2017). Enrolling in the closest school or not? Implications of school choice decisions for active transport to school. Journal of Transport and Health, 6, 347-357. https://doi.org/ 10.1016/j.jth.2017.05.006.

Martono, N. (2019). Sekolah inklusi sebagai arena kekerasan simbolik. Sosiohumaniora, 21(2), 150-158.

Mary, T.A., \& Jeba Seelan, A.U.S. (2014). Student learning behavior and academic achievement: Unraveling its relationship. Indian Journal of Applied Research, 4(12), 57-59. https:// doi.org/10.15373/22778160.

Moldes, V.M., Biton, C.L., Gonzaga, D.J., \& Moneva, J.C. (2019). Students, peer pressure and their academic performance in school. International Journal of Scientific and Research Publications, 9(1), 2250, 3153. http://dx.doi.org/10.29322/IJSRP.9.01.2019.p8541. 
MeenuDev, P.D. (2016). Factors affecting the academic achievement: a study of elementary school students of NCR Delhi, India. Journal of Education and Practice, 7(4), 70-74.

Muammar, M. (2019). Problematika Penerimaan Peserta Didik Baru (PPDB) dengan Sistem Zonasi Di Sekolah Dasar (SD) Kota Mataram. El Midad, 11(1), 41-60.

Nurdin, N. (2018). Mendusta dengan SKTM palsu demi sekolah anak. https:// regional.kompas.com/read/2018/07/11/08071611/mendusta-dengan-sktm-palsu-demisekolah-anak-1 ?page $=$ all.

Nabaiho. (2018). Implementasi kebijakan Penerimaan Peserta Didik Baru (PPDB) online tingkat sekolah menengah atas di Dinas Pendidikan Provinsi Sumatera Utara. Skripsi. Universitas Sumatera Utara.

OECD/Asian Development Bank. (2015). Education in Indonesia: Rising to The Challenge. Paris: OECD Publishing.

Okafor, C.A., Maina, J.J., Stephen, H. \& Ohambele, C.C. (2016). Impact of school environments on academic performance: Feedback from senior secondary school students. In Ebohon, O.J., Ayeni, D.A, Egbu, C.O, and Omole, F. K. Procs. of the Joint International Conference (JIC) on 21st Century Human Habitat: Issues, Sustainability and Development, 21-24 March 2016, Akure, Nigeria, page number 1175-1182.

Oktaviari, V. (2020). Model sistem zonasi dari perspektif teori keadilan sosial John Rawls (Studi pada Sekolah Menengah Atas di Blitar Raya). Disertasi, Universitas Muhammadiyah Malang.

Olayemi, W. (2018). The influence of school types, class classifications and gender on academic achievement in economics among high school students: A comparative analysis. International Journal of Progressi ve Sciences and Technologies (IJPSAT), 8(2), 120-128.

Permendikbud Nomor 14 Tahun 2018 tentang Penerimaan Peserta Didik Baru Pada Taman KanakKanak, Sekolah Dasar, Sekolah Menengah Pertama, Sekolah Menengah Atas, Sekolah Menengah Kejuruan, atau Bentuk Lain Yang Sederajat. https://jdih.kemdikbud.go.id/arsip/ Permendikbud_Tahun2018_Nomor14.pdf.

Permendikbud Nomor 44 Tahun 2019 tentang Penerimaan Peserta Didik Baru pada Taman KanakKanak, Sekolah Dasar, Sekolah Menengah Pertama, Sekolah Menengah Atas, dan Sekolah Menengah Kejuruan.

Põder, K., Lauri, T., \& Veski, A. (2016). Does school admission by zoning affect educational inequality? A Study of family background effect in estonia, Finland, and Sweden. Scandinavian Journal of Educational Research, 61(6), 668-688. https://doi.org/10.1080/ 00313831.2016 .1173094$.

Purwati, D., Irawati, I., \& Adiwisastra, J. (2018). Efektivitas Kebijakan Penerimaan Peserta Didik Baru Sistem Zonasi Bagi Siswa Rawan Melanjutkan Pendidikan. Jurnal IImiah IImu Administrasi Negara, 6(1), 1-7.

Ratnawati, D., Suwitri, S., \& Rengga, A. (2013). Implementasi Peraturan Daerah Kabupaten Kudus Nomor 2 Tahun 2010 Tentang Wajib Belajar 12 (Dua Belas) Tahun di Kabupaten Kudus. Journal Of Public Policy And Management Review, 2(3), 1-10. https://doi.org/ 10.14710/jppmr.v2i3.3073. 
RRI. (2019). Sistem zonasi penerimaan siswa baru, dapat turunkan reputasi sekolah. http:// rri.co.id/pontianak/post/berita/409024/daerah/ sistem_zonasi_penerimaan_siswa_baru_dapat_turunkan_reputasi_sekolah.html.

Setiawan, Z.A. (2019). Sejumlah orangtua kecewa sistem zonasi, percuma ikut bimbel yang dipilih yang jaraknya dekat!. https://wartakota.tribunnews.com/2019/06/18/sejumlahorangtua-kecewa-sistem-zonasi-percuma-ikut-bimbel-yang-dipilih-yang-jaraknya-dekat.

Safarah, A.A., \& Wibowo, U.B. (2018). Program zonasi di sekolah dasar sebagai upaya pemerataan kualitas pendidikan di Indonesia. Lentera Pendidikan: Jurnal Ilmu Tarbiyah Dan Keguruan, 21(2), 206-213. https://doi.org/10.24252/Ip.2018v21n2i6.

Safitri. (2019). Mendikbud Paparkan Kelebihan Sistem Zonasi di PPDB. https://news.detik.com/ berita/d-4591338/mendikbud-paparkan-kelebihan-sistem-zonasi-di-ppdb.

Taufiqurokhman. (2014). Kebijakan publik, pendelegasian tanggungjawab negara kepada presiden selaku penyelenggara pemerintahan. Jakarta Pusat: Fakultas Ilmu Sosial dan Ilmu Politik Universitas Moestopo Beragama (Pers).

Vito, B., Krisnani, H., \& Risna, R. (2015). Kesenjangan pendidikan desa dan kota. Prosiding Penelitian Dan Pengabdian Kepada Masyarakat, 2(2), 247-251. https://doi.org/10.24198/ jppm.v2i2.13533.

Wahyuni, D. (2018). Pro kontra sistem zonasi penerimaan peserta didik tahun ajaran 2018/2017. Info Singkat, 10(14), 13-18.

Wiles, R., Crow, G., \& Pain, H. (2011). Innovation in qualitative research methods: A narrative review. Qualitative research, 11(5), 587-604. https://doi.org/10.1177/ 1468794111413227.

Wilson, E.J., Marshall, J., Wilson, R., \& Krizek, K.J. (2010). By foot, bus or car: Children's school travel and school choice policy. Environment and Planning A, 42(9), 2168-2185. https:// doi.org/10.1068/a435. 